\title{
laborhifórico
}

ISSN 2359-6910

https://revistas.ufrj.br/index.php/lh/

ARTIGO

Recebido em 2 de julho de 2019

Aprovado em 4 de setembro de 2019

\section{Esquemas construcionais no português arcaico: um estudo sobre X-ada1, X-ada2, X-ado, X-do, X-da}

Constructional schemes in Archaic Portuguese:

a study on X-ada1, X-ada2, X-ado, X-do, X-da

DOI: https://doi.org/10.24206/lh.v6i1.31294

Juliana Soledade Doutora em Letras e Linguística pela Universidade Federal da Bahia. É Professora Associado da Universidade Federal da Bahia, em exercício atualmente na Universidade de Braślia. É Professora Permanente do Programa de Pós-graduação em Língua e Cultura (PPGLinc) da Universidade Federal da Bahia e do Programa de Pós-graduação em Linguística (PPGL) da Universidade de Brasília. 


\section{RESUMO}

O presente trabalho intenta contribuir para a divulgação e avanço do conhecimento linguístico acerca da sufixação no período arcaico da língua portuguesa, a partir de análises que têm como base os aportes descritivistas, cognitivistas e construcionais (BOOIJ, 2010; GONÇALVES, 2016; SOLEDADE, 2013). Uma vez que a sufixação no português arcaico é demasiadamente vasta, neste artigo, iremos tratar dos esquemas sufixais $X-a d a_{1} X$-ada,$X$-ado, $X$-do, X-da. Para constituir o corpus da primeira fase, observamos fontes secundárias, i.e., glossários elaborados com base em textos do período arcaico do português e, para a segunda fase, fontes primárias, ou seja, edições de textos arcaicos em prosa datados entre o século XV até meados do XVI.

Palavras-chave: Português arcaico. Sufixação. Morfologia Construcional. Polissemia. Nominalizações.

\section{ABSTRACT}

The present work intends to contribute to the dissemination and advancement of linguistic knowledge about suffixation in the archaic period of the Portuguese language, based on descriptivist, cognitivist and constructive contributions (BOOIJ, 2010; GONÇALVES, 2016; SOLEDADE, 2013). Since the suffixation in Archaic Portuguese is too vast, in this article, we will deal with the suffix schemes $X-a d a_{1} X-a d a_{2}, X-a d o, X-d o, X-d a$. In order to constitute the corpus of the first phase, we look at secondary sources, that is, glossaries elaborated on the basis of texts from the archaic period of Portuguese, and we observe, for the second phase, primary sources, that is, editions of archaic prose texts dated from XV until mid-XVI century.

Keywords: Archaic Portuguese. Suffixation. Constructional morphology. Polysemy. Nominalizations. 


\section{Apresentação}

O presente estudo tem como foco contribuir para a divulgação e avanço do conhecimento linguístico acerca da sufixação no período arcaico da língua portuguesa trazendo análises com aportes descritivista e cognitivistas. Nesse artigo, iremos tratar de alguns sufixos que se integravam a esquemas construcionais em uso entre os séculos XIII e XVI, especificamente os esquemas $X-a d a_{1} X-a d a_{2}, X-$ ado, $X-d o, X-d a$.

A investigação dos processos de formação de palavras no período arcaico se revela uma importante contribuição para a compreensão dos processos cognitivos que deram origem a esquemas construcionais que herdamos e que atualizamos ao longo do tempo. O período em que se reconhece o chamado português antigo/galego-português/ português arcaico é um momento da língua em que muitas homonímias e sinonímias se apresentavam, acarretando mudanças significativas na morfologia derivacional em épocas posteriores.

Além disso, os padrões derivacionais do português arcaico apresentam dois aspectos importantes: uma feição conservadora, que se revela através do uso de raízes e afixos que pertenciam à língua latina e que, contudo, não permaneceram na língua portuguesa no decorrer de sua história, e uma feição inovadora, explicitada pelas criações morfológicas próprias do período, que, do ponto de vista semântico, apontam para processos de projeções metafóricas e metonímicas na organização hierárquica dos esquemas construcionais.

A linguística cognitiva é, pois, a linha teórica que utilizamos para a análise das informações oferecidas pelos dados. Nesse sentido, por um lado, observamos a língua a partir dos seus usos concretos, considerando que o conhecimento linguístico emerge e se estrutura a partir do uso da linguagem; por outro, entendemos que fenômenos como esquematicidade e frequência de uso são basilares na organização mental do léxico, em geral, e do léxico derivacional, em específico.

Desse modo, este estudo se organiza em quatro seções: a primeira dedicada a explicitar como os pressupostos da linguística cognitiva e da morfologia construcional são tomados para a análise dos dados; a segunda, que dá conta de como foi constituído o corpus no qual se baseiam as nossas reflexões; a terceira, que traz a análise de alguns esquemas construcionais, por ora estudados ${ }^{1}$; e, por fim, a quarta e última seção que apresenta algumas considerações finais.

\footnotetext{
${ }^{1}$ A pesquisa que realizamos neste artigo faz parte de um projeto de reanálise, sob a perspectiva da LC e MC, dos dados referentes aos usos de 64 sufixos no período arcaico da língua portuguesa, estudados por Soledade (2004).
} 


\title{
1. A esquematicidade e a frequência de uso na perspectiva cognitivista
}

A linguística cognitiva (LC), embora nasça no seio do gerativismo, terá como esteio pressupostos que conduzem o pensamento linguístico para o polo oposto das teorias formalistas, sendo, portanto, uma teoria dita funcionalista. Uma das ideias basilares do funcionalismo é a de que há um relacionamento motivado entre forma linguística e função comunicativa, tratando a língua como uma estrutura maleável que se adapta, continuamente, às necessidades de expressão de pensamentos e interação entre os homens. A linguística cognitiva, partindo dessa premissa, entenderá que existem princípios cognitivos gerais que são compartilhados pela linguagem e por outras capacidades cognitivas (como atenção/foco, percepção, memória) e que a linguagem se organiza em estruturas conceptuais, de onde deriva, portanto, a perspectiva semanticocêntrica.

Dentro da LC, com base na gramática das construções (LANGACKER, 1987; GOLDBERG, 1995) desenvolveu-se a morfologia construcional (MC) (BOOIJ, 2010, 2012, 2014).

\begin{abstract}
$\mathrm{Na}$ gramática das construções, a gramática representa um inventário de unidades complexas que unificam forma-significado-função, em que as palavras se distinguem das construções gramaticais apenas em relação à sua complexidade interna. O inventário das construções não é desestruturado; é mais como um mapa do que uma lista de compras. Elementos deste inventário estão relacionados através de hierarquias de herança, contendo mais ou menos padrões gerais. (MICHAELIS; LAMBRECHT, 1996, p. 216 [tradução nossa] $)^{2}$
\end{abstract}

Desse modo, ao nos afiliarmos a esse pensamento, assumimos que: 1) existem generalizações morfológicas específicas que não podem ser transferidas a níveis fonológicos ou sintáticos; 2) palavras complexas são armazenadas no mapa lexical até que sejam depreendidos os esquemas por generalização/abstração; 3) esquemas construcionais morfológicos, uma vez abstraídos, economizam a memória do falante que já não precisa armazenar palavras previsíveis de um dado esquema, podendo gerá-las online; e 4) esquemas podem gerar palavras complexas que serão armazenadas em mapas associativos, caso sofram alterações semânticas de natureza idiossincrática (quando são afetadas por certos tipos de polissemia não previsíveis).

Na perspectiva da morfologia construcional, ser um signo linguístico motivado, isto é, não arbitrário, é uma propriedade gradiente de palavras complexas. Essa propriedade se correlaciona com o

\footnotetext{
2 "In Construction Grammar, the grammar represents an inventory of form-meaning-function complexes, in which words are distinguished from grammatical constructions only with regard to their internal complexity. The inventory of constructions is not unstructured; it is more like a map than a shopping list. Elements in this inventory are related through inheritance hierarchies, containing more or less general patterns."
} 
grau em que são preservadas as características formais e semânticas relevantes do esquema de formação de palavras e o grau de conservação da herança semântica da palavra base. Quanto maior for a preservação dessas propriedades, mais motivada será a palavra complexa.

A esquematicidade é tomada por Langacker (1987, p. 73-75) como uma das mais centrais capacidades da cognição humana que se constitui através da habilidade de generalização, ou seja, esquemas linguísticos ou conceituais são extraídos a partir de generalizações que permitem selecionar partes relevantes de uma construção (linguística ou conceitual) e desprezar as menos relevantes. "Todos os conceitos humanos são esquemáticos em algum grau, abstraindo as diferenças das experiências ou pensamentos particulares nos quais se baseiam". [tradução nossa] (TUGGY, 2007, p. $84)^{3}$.

Booij afirma que "esquemas morfológicos são adquiridos com base em um conjunto de palavras complexas memorizadas, isto é, palavras complexas totalmente especificadas" (BOOIJ, 2012, p. 4)4 [Tradução nossa]. Assim, por exemplo, o falante do português primeiro adquire nomes individuais em -ada, como feijoada, e, após uma exposição suficiente a um conjunto de palavras com semelhante formação, o esquema para a construção de nomes em -ada, associado à noção de 'alimentos feito de $\mathrm{X}$, pode ser apreendido.

Segundo Booij (2010), esquemas construcionais podem ser descritos como capazes de: (i) especificar as informações previsíveis acerca das classes de itens lexicais complexos totalmente enquadrados no esquema, bem como especificar como novas palavras complexas podem ser construídas; e (ii) abarcar subesquemas que incorporam propriedades particulares adicionais ou apresentam propriedades mais específicas de subclasses de itens lexicais.

Então, esquemas morfológicos não devem ser vistos como mecanismos formais para alcançar representações lexicais maximamente particularizadas (por exemplo, lexicalizações idiossincráticas). Em vez disso, têm duas outras funções: por um lado, motivam a existência de um conjunto relevante de palavras complexas e, por outro, preveem como esse conjunto pode ser estendido. Assim sendo, esquemas são um componente de máxima relevância para organização mental do léxico.

Entender como se moldavam os padrões esquemáticos no período arcaico, quando ainda não havia convencionalização e fixação de certas formas derivadas no léxico da língua, é, pois, uma tarefa que pode revelar aspectos importantes sobre a constituição histórica do sistema lexical do português. Uma das evidências que podemos encontrar em textos desse período é o acesso online a esquemas

\footnotetext{
3 "All human concepts are schematic in some degree, abstracting away from the differences in the particular experiences or thoughts on which they are based."

${ }^{4}$ Morphological schemas are acquired on the basis of a set of memorized complex words, i.e. fully specified complex words."
} 
construcionais, uma vez que é possível encontrar em um mesmo autor tipos variantes, que chamamos de doublets morfológicos (SOLEDADE, 2004), que podem, inclusive, aparecer em um mesmo parágrafo, como se pode ver no exemplo a seguir da Crónica de D. Pedro de Menezes, escrita por Gomes Eanes Zurara: “... eu nom poderia escrever sem lagrimas a espidiçam que estas gemtes fezerão hũas das outras, ...” (CDPM, p. 210) e “... a ora daquella partyda, foy amtre elles hũ espedimemto tam doroso, ...” (CDPM, p. 210). Nesse exemplo, as formas espediçam e espedimento ('despedida') são construídas acionando esquemas nominalizadores diferentes sobre uma mesma base verbal espedir.

Se esquemas construcionais são adquiridos a partir do conhecimento e armazenamento mental de um conjunto de palavras complexas que instanciam os padrões de construção que possibilitam a geração de novos itens lexicais, no português arcaico esse conjunto ainda estava em formação ${ }^{5}$, o que possibilitava a variação de escolhas e acessos a esquemas. Isso, contudo, não quer dizer que não houvesse uma organização hierárquica, ela só estava mais maleável do que o normal.

A partir da concepção de que a gramática das línguas emerge do uso, um outro fator será de extrema importância para compreendermos a organização das redes que constituem o léxico do português arcaico: a frequência de uso. Obviamente a frequência enquanto um importante fator para a construção da gramática de uma língua perpassa a compreensão da relevância do aspecto pragmático e discursivo para o funcionamento dessa gramática.

O modelo baseado no uso é um modelo de representação gramatical no qual o uso da língua determina a representação gramatical. Especificamente, a frequência de uso e a similaridade de forma e significado são fatores determinantes para a organização do conhecimento gramatical na mente. (CROFT, 2007, p. 499) 6 [tradução nossa]

Em termos básicos, pode-se afirmar com Brown (1965), Rosch et al. (1976), Downing (1977) e Bybee (1995) que quanto mais frequente for um constructo linguístico mais entranhado (cf. entrenchment) ele estará na gramática da língua e vice-versa.

Com base nas propostas de Bybee (1985, 1995, 2001), Croft argumenta que uma das hipóteses relevantes para a teoria da língua baseada no uso, adotada pela LC, é a de que a prolificidade de um esquema está relacionada à frequência das instanciações que servem de modelo para esse esquema, isso quer dizer que a frequência de uso de um dado formativo em várias instanciações determina o quão capaz de gerar novas instanciações será o esquema abstraído a partir de generalização feita sobre esse

\footnotetext{
${ }^{5}$ Esse aspecto é bastante evidenciado pelo número abundante de doubltes morfológicos nos textos desse período, como bem demonstra Soledade (2005).

6 "The usage-based model is a model of grammatical representation in which language use determines grammatical representation. Specifically, frequency of use and similarity of form and meaning are the determining factors for the structure of grammatical knowledge in the mind."
} 
elemento recorrente. Assim, com Bybee (1985) argumentamos que a frequência do modelo determina a produtividade de um esquema.

Quando analisamos uma língua em um dado momento histórico, o número de criações inovadoras (falando de morfologia, geradas por processos morfológicos de construção) será sempre inferior ao de formas herdadas, por sua vez, quanto maior for o número de formas herdadas com um determinado formativo, mais forte será o modelo capaz de gerar esquemas que permitam criar novas instanciações.

Por exemplo, no português arcaico, as ocorrências de nominalizações em -çom e -mento herdadas do latim são muito superiores às formas herdadas em -nça -ncia, o resultado é que as nominalizações geradas/criadas no PA utilizam em número muito superior aqueles dois sufixos e, raramente, o último. Esse fenômeno se desdobra até os dias atuais, quando as nominalizações em -ção e -mento são claramente preferidas em detrimentos dos alomorfes $-n c ̧ a \sim-n c i a$.

Acerca dessa frequência de uso, consideramos, com Soledade (2001) e Viaro (2008), que estão implicados os conceitos de produtividade $\mathrm{X}$ vitalidade / prolificidade $\mathrm{X}$ vitalidade ${ }^{7}$, respectivamente.

Esses dois conceitos devem sempre ser vistos por meio de um parâmetro de gradualidade. $\mathrm{O}$ grau de prolificidade deve ser julgado pela quantidade de palavras herdadas em que figure um dado formativo, assim, por exemplo, se pode dizer que o prefixo latino $a b$-, embora tenha alguma prolificidade no português (obstante, obstar, obscuro, obstruir, obstáculo), já não apresenta vitalidade, sendo, portanto, o grau de vitalidade relacionado com o número de formas novas geradas ou prováveis de serem geradas por aquele formativo, numa dada sincronia. No caso de $o b-$, podemos dizer que, atualmente, ele não apresenta nenhum grau de vitalidade. $O$ que não implica que o esquema construcional que o colocaria ativo não possa ser acionado e retomado produzindo novas formas a depender das necessidades comunicativas dos falantes.

\section{De onde vieram os dados?}

Quando estamos estudando uma sincronia pretérita de uma língua, não nos é possível constituir um corpus de acordo com os nossos interesses de investigação; ele já se encontra delimitado e restrito aos documentos existentes. No caso do período arcaico, essa documentação já é bastante determinada, por ser o período em que se inicia a produção de documentos escritos em português.

\footnotetext{
${ }^{7}$ Cremos que a substituição do termo produtividade por prolificidade é muito bem-vinda, uma vez que aquele já estava bastante comprometido com as concepções gerativistas do termo.
} 
Em um trabalho que procura descrever o quadro linguístico de um momento histórico bastante extenso de uma língua, como é o nosso caso, quase quatro séculos, não poderíamos almejar abranger toda a documentação remanescente do período arcaico, mas sim procurar constituir aquilo que Mattos e Silva (1989, p. 39) denomina de um corpus representativo.

Devido à impossibilidade de se fazer um trabalho exaustivo referente aos textos arcaicos propriamente ditos, optamos por constituir, para a primeira fase do português arcaico, um corpus a partir de glossários (publicados ou não) constantes em edições de documentos do período. Para a segunda fase, optamos por recolher os dados a partir dos próprios textos, abrindo mão da sistematicidade dos glossários em favor da variedade de dados e de um maior acesso aos possíveis sentidos das instanciações dentro de um contexto de uso.

Para constituir o corpus da primeira fase, portanto, observamos fontes secundárias, i.e., glossários elaborados com base em textos do período arcaico do português e observamos, para a segunda fase, fontes primárias, ou seja, edições de textos arcaicos em prosa datados entre o século XV até meados do XVI.

Para selecionar essas fontes, foram consideradas as observações de Mattos e Silva acerca da constituição de um corpus representativo para o estudo do português arcaico. Conforme a autora, os documentos desse período podem ser divididos em três categorias: a) a documentação poética, i.e., a lírica galego-portuguesa ou o cancioneiro medieval português; b) a documentação em prosa não literária, ou seja, a documentação de natureza jurídica; e c) a documentação em prosa literária entendida em seu sentido amplo em oposição aos textos jurídicos, quer em textos escritos em português quer em textos traduzidos do latim ou de outras línguas.

Desses textos foram extraídas 4.781 ocorrências de palavras derivadas por sufixação. Esse corpus serviu à tese de doutoramento desta autora, de natureza exclusivamente descritivista e que agora serve de base para uma nova análise da sufixação no período arcaico da língua portuguesa tendo como referencial teórico a linguística cognitiva e mais especificamente a morfologia construcional.

\section{Analisando esquemas do português arcaico}

\subsection{O esquema $X$-ada}

Os sufixos -ada tem sua origem respectivamente em -ata, o correspondente feminino de -atus, sufixo latino formador de substantivos e adjetivos deverbais. 
No latim, esses sufixos teriam sua origem no particípio passado latino, como coloca Said Ali (1964, p. 237), ao dizer que no português existem:

substantivos abstratos ou concretos cuja criação se deve à simples adaptação semântica do particípio do pretérito de certos verbos. (...). Contudo, ainda no latim, algumas lexias perderam a identidade entre o derivado e os particípios verbais" (SAID ALI, 1964, p. 237).

Assim sendo, -atus e -ata passaram a integrar o sistema derivacional como elementos morfolexicais sufixais, com autonomia para derivar não apenas adjetivos a partir de verbos, mas também substantivos a partir de substantivos.

Segundo Said Ali (1964), essa mudança afetou, sobretudo, o sufixo -ata, que assumiu uma vitalidade significativa no latim, dando origem ao -ada no português arcaico e, podemos verificar que este se manteve no português contemporâneo.

Nos dados do PA, a polissemia do sufixo - ada se revela nos seguintes subesquemas relacionados por uma noção de quantidade:

$<\left[\mathrm{X}_{\mathrm{Si}}-\mathrm{ada}\right]_{\mathrm{Sj}} \leftrightarrow\left[\text { conjunto/quantidade relacionado ao } \mathrm{SEM}_{\mathrm{Si}}\right]_{\mathrm{Sj}}>(1)$

$<\left[\mathrm{X}_{\mathrm{Si}}-\mathrm{ada}\right]_{\mathrm{Sj}} \leftrightarrow\left[\text { grande quantidade relacionada ao } \mathrm{SEM}_{\mathrm{Si}}\right]_{\mathrm{Sj}}>(1)$

$<\left[\mathrm{X}_{\mathrm{Si}}-\mathrm{ada}\right]_{\mathrm{Sj}} \leftrightarrow\left[\text { duração prolongada relacionada ao } \mathrm{SEM}_{\mathrm{Si}}\right]_{\mathrm{Sj}}>(2)$

$<\left[\mathrm{X}_{\mathrm{Si}}-\mathrm{ada}\right]_{\mathrm{Sj}} \leftrightarrow\left[\text { medida relacionada ao } \mathrm{SEM}_{\mathrm{Si}}\right]_{\mathrm{Sj}}>(2)$

O sufixo -ada foi empregado com sentido de coletivo em uma ocorrência encontrada na segunda fase do português arcaico, a forma mesnada. Esta tem uma provável origem francesa, e esta, por sua vez, do latim * mansionata < mansio, onis. O seu sentido segundo o DDGM seria 'conjunto de hombres a sueldo y que vivían en la casa del señor', e segundo Houaiss 'tropa de soldados, mercenários'. Essa ocorrência aponta para uma primitiva aplicação do sufixo no latim, com o sentido de 'coletivo', que seria talvez uma das fontes da qual partiriam os seus outros sentidos em expansão de natureza polissêmica.

Assim, com uma criação vernacular do português arcaico, encontramos dineirada na primeira fase, em que o sufixo expressa a noção 'grande quantidade relacionada ao sema de X'. Nesse caso a relação de composicionalidade é explícita pois é a base o objeto de quantificação, já no caso de mesnada não, pois o sentido da base é o locativo mansio, onis, 'casa', que, por sua vez, é o lugar que hospeda abriga esse conjunto de homens pagos para lutar, daí termos uma instanciação de caráter 
metonímico uma vez que o recipiente (casa, abrigo) é tomada como referência ao 'conjunto de homens, tropa'.

Um novo sentido, com uma extensão de caráter metafórico, também surge nos dados com o sufixo -ada, quando ele expressa 'duração prolongada de X': iornada, invernada e jornada, que ocorrem tanto na primeira quanto na segunda fases do PA. Embora jornada venha do provençal, invernada parece ser uma criação vernacular do período arcaico, provavelmente cunhada a partir do modelo provido pela instanciação de origem provençal. A metáfora aqui incide sobre o esquema como um todo já que a noção de quantidade numérica, contável e, portanto, concreta, dá origem a um sentido mais abstrato referente à 'quantidade de tempo'.

O sufixo -ada aparece também na lexia criada no período arcaico queijada, em que o sentido pode ser interpretado com 'alimento feito uma quantidade de X', sentido esse que terá grande vitalidade na língua portuguesa em períodos subsequentes (laranjada, feijoada, bacalhoada etc.).

A noção de quantidade também se reflete em termos cuja noção pode ser interpretada como 'medida equivalente a X'. Este se apresentou em duas ocorrências, uma originária do latim pollicata > pollegada e uma criação vernacular do português arcaico: braçada.

Por fim, vale dizer que alguns autores, como Ali (1964), Rio-Torto (1998) e Rocha (1998), descrevem outras possibilidades de sentido, para o sufixo -ada, no português contemporâneo, por exemplo "porção contida num objeto X" (ex: colherada, garfada). Contudo, a não ocorrência dessa acepção nos nossos dados pode indicar que essa seja uma possibilidade de sentido que o sufixo desenvolveu posteriormente ao século XVI, por outro lado, não significa que não possamos encontrála, no período arcaico, em um estudo mais amplo, com um maior número de lexias.

\subsection{O esquema $X-a d a_{2}$ ou $X-(a) d a$ : um caso para reflexão}

A noção de maior expressão de um suposto sufixo -ada no português arcaico foi a de 'ação praticada com X'. Essa se apresentou em quatro ocorrências na primeira fase: em agulhada, dentada, palmada e punhada e, também, em quatro ocorrências na segunda fase como em fachada, llamçadas, punhada e punhaladas. Todos os exemplos são criações do período arcaico, não sendo encontrado nos dados nenhum exemplo desse sentido com origem no latim.

A relação com a noção de quantidade aqui pode ser feita através de uma leitura de como esses atos podem ser praticados, normalmente, com reiteração, seja a fim de letalidade (como em facada), seja a fim de alcançar o objetivo (como em dentada). Se essa hipótese for comprovada, teremos um esquema relacionado ao de quantidade: 


\section{$<\left[\mathrm{X}_{\mathrm{Si}}-\mathrm{ada}\right]_{\mathrm{Sj}} \leftrightarrow\left[\text { ação reiterada relacionada ao } \mathrm{SEM}_{\mathrm{Si}}\right]_{\mathrm{sj}}>(7)$}

Por outro lado, essas ocorrências podem se tratar de formações de natureza participial, a partir de lançar (lat. lanceo -are) e teríamos lançada 'ação de jogar a lança', donde, 'ferimento feito com lança'. No PA, há ocorrências do verbo punhar (do lat. pungno -are) e do verbo agulhar, de agulha (acucula-) + ar (Dicionário de verbos do CIPM), de onde tiraríamos agulhada 'ação de espetar com agulha'; por analogia viria então punhada 'ação praticada com o punho, soco'.

No âmbito da morfologia lexical, com base em Sandmann (1987), para o tratamento das demais formações, a essas semelhantes, teríamos de considerar um salto de etapas na criação do verbo. Assim, assumindo a existência de ações do tipo dentar 'dar dentadas, mordidas em; morder', palmar 'assentar, aplicar golpe semelhante a palmada' (hoje registrados no Houaiss, mas sem registro no PA), *facar 'golpear com faca' e *punhalar 'golpear com punhal' (sem registros no Houaiss), teríamos, nos derivados, expressões participais correspondentes. Nesse caso, o esquema não teria relação com os anteriormente descritos e passaria a ter como base elementos da classe verbal:

$$
<\left[\mathrm{X}_{\mathrm{Vi}_{\mathrm{i}}}-(\mathrm{a}) \mathrm{da}\right]_{\mathrm{Sj}} \leftrightarrow\left[\text { resultado da ação de } \mathrm{SEM}_{\mathrm{Vi}}\right]_{\mathrm{Sj}}>(7)
$$

Porém, a análise sob a perspectiva cognitivista e construcional nos aponta um caminho diferente. Considerando, com base na concepção da teoria da entrada plena, que esquemas podem ser abstraídos a partir de um conjunto de instanciações que lhes servem como modelo, podemos admitir que, uma vez consolidados e frequentes os modelos/instanciações lançada, agulhada e punhada, o falante do português no período arcaico poderia ter generalizado o esquema:

$$
<\left[\mathrm{X}_{\mathrm{Si}}-\mathrm{ada}\right]_{\mathrm{Sj}} \leftrightarrow\left[\text { ação praticada com } \operatorname{SEM}_{\mathrm{Si}}\right]_{\mathrm{Sj}}>(7)
$$

Nesse esquema, se subentende uma relação direta na inserção dos substantivos (lança, agulha, punho, palma, faca, dente e punhal) no esquema $\left[\mathrm{X}_{\mathrm{Si}}-\mathrm{ada}\right]_{\mathrm{Sj}}$. Ressalte-se que a vitalidade desse esquema no português contemporâneo é bastante significativa (por exemplo: cabeçada, canelada, canetada, chinelada, vassourada, alfinetada, bolada) e que os itens lexicais encaixados no esquema são sim substantivos aos quais não temos relacionados um verbo da primeira conjugação -ar. 


\subsection{O esquema $\mathrm{X}$-ado}

O sufixo -ado com o sentido de 'provido de $\mathrm{X}$ ' ou 'provido de qualidade relativa a X', já encontra expressão no latim, por exemplo barvado do latim barbatus, a, um 'provido de barba; idoso; (animal) coberto de pelos; bode'; leterados do latim litteratus, a, um 'provido do saber das letras; sábio, douto, letrado'. Como disse Said Ali, o -atus latino já se prestava a formações adjetivais cuja base não fosse um verbo, se descolando das formações participiais, assim o esquema $<\left[\mathrm{X}_{\mathrm{Si}}-\mathrm{ado}\right]_{\mathrm{Sj}} \leftrightarrow[$ 'provido de (qualidade) relacionada a $\left.\mathrm{SEM}_{\mathrm{Si}}\right]_{\mathrm{Sj}}>$ origina, por exemplo, no português arcaico: demoniado, na primeira fase e ladrilhados, na segunda.

Outro sentido veiculado já no latim pelo sufixo -atus, era o de 'entidade, organização, colégio', como em bispado do lat. episcopatus 'diocese, episcopado'. $\mathrm{O}$ esquema então seria $<\left[\mathrm{X}_{\mathrm{Si}}-\mathrm{ado}\right]_{\mathrm{Sj}} \leftrightarrow$ [entidade, organização, colégio relacionado a $\left.S_{E M_{S i}}\right]_{\mathrm{Sj}}$, do qual se teriam construído no período arcaico: arçobispado e mestrado.

A relação semântica entre esses dois esquemas não foi por nós aventada. Ao que parece sufixos de natureza adjetival, como o caso dos participais em -atus, -atas, possuem uma relativa abertura para ampliação de sentidos em direções variadas.

\subsection{Os esquemas $\mathrm{X}-d$ e e $X-d a$}

Tratemos, então, dos elementos com origem nos participiais propriamente ditos.

O sufixo $-d o$, do latim -tus, a, um, formador de adjetivos e substantivos a partir de bases verbais apresentou grande prolificidade e vitalidade no período arcaico, ou seja, tanto formas já cunhadas na língua latina, quanto inovações vernaculares fazem parte do extenso conjunto de instanciações do esquema de particípio passado.

O sentido mais usual a que se presta originariamente o sufixo é o de 'qualidade relacionada ao sentido de X', gerando o esquema:

$$
<\left[\mathrm{X}_{\mathrm{Vi}}-\mathrm{do} / \mathrm{a}\right]_{\mathrm{Aj}} \leftrightarrow\left[\text { atributo relacionado ao } \mathrm{SEM}_{\mathrm{Vi}_{\mathrm{i}}}\right]_{\mathrm{Aj}}>
$$

Das ocorrências levantadas, 72 foram encontradas na primeira fase do PA. São exemplos dessas ocorrências: acomendado, acostado, aguisado, coitado, cousido, desguisado, desnuados, enrugado, menguado, opremudo, podrido, temudo. As formas originárias do latim apresentam-se em número bem menor, apenas duas, a saber: amado (do lat. amatus, a, um) e partido (do lat. partitus, a, um). 
$\mathrm{Na}$ segunda fase, esse cenário se mantém. A diferença é que as formas participais de segunda conjugação, que na primeira fase predominavam com a terminação -udo, já se encontram padronizadas em -ido. Foram identificadas 80 ocorrências de adjetivos participias formadas na língua arcaica, entre elas: aficados, afiuzada, blasfemado, degredados, depenada, desbaratada, filhada, gallardoadas, gasalhado, myngoadas, perlongadas, temorizado. Formados no latim, foram encontrados cinco adjetivos participiais: adorado (do lat. adoratus, a, um), firmada (do lat.firmatus, a, um), laureado (do lat. laureatus, a, um), quadrada (do lat. quadratus, a, um), sagrado (do lat. sacratus, a, um).

Os particípios empregados como substantivos já se mostravam presentes no latim. Esse tipo de processo emana de um processo cognitivo denominado de focalização, decorrente da percepção óptica que apreende as imagens através de um dualismo figura e fundo, em que a figura é o elemento focado na percepção visual e o fundo é o contexto mais amplo em que a figura se vê inserida. Quando tratamos da relação substantivo-adjetivo, na linguagem, percebemos que a focalização imprime sobre o substantivo a impressão de figura, cabendo ao adjetivo o papel de fundo. Contudo, o alçamento dos adjetivos à posição de figura se revela um processo dos mais produtivos na língua, sendo relevante destacar que nos parece que qualquer adjetivo pode ser transcategorizado para substantivo (portanto, figura) a depender das necessidades comunicativas do falante. Por exemplo, um adjetivo prototípico como feliz pode aparecer como núcleo de um SN, como no título de um livro de 1700, de autoria do P. Theodoro D'Almeida: O feliz independente do mundo e da fortuna ou a arte de viver contente em quaesquer trabalhos da vida.

No caso dos adjetivos de caráter relacional de base verbal, cujo sentido parece ser bastante genérico, uma vez que implica atributos de natureza variada, a focalização destes como substantivos não parece ser algo inesperado. Por sua vez, os substantivos decorrentes desse processo assumem sentidos muito diversificados, sendo quase impossível estabelecer um esquema geral com uma contraparte semântica especificada. Isso se deve ao caráter atomístico de cada processo de focalização.

Em relação aos particípios, a focalização como substantivos parece se aplicar de forma mais efetiva em instanciações femininas, ou seja, com o sufixo $-d a$.

Nos dados levantados, foram encontradas dez ocorrências na primeira fase, entre as quais: albergada 'pousada', alçada 'recurso', amada 'Virgem Maria', bastida 'trincheira', cavalgada 'operação militar a cavalo', ferida 'golpe, chaga', guarida 'cura', madrugada 'alvorecer', nomeada 'fama', pousada 'hospedaria'; e oito ocorrências na segunda fase: armada 'frota', bastidas 'trincehiras', entrada 'chegada', ferida 'ferimento', morada 'moradia', partida 'saída', pousada 'hospedagem'.

Com a forma do masculino, através do sufixo $-d o$, a focalização se deu em menor número no português arcaico. $\mathrm{Na}$ primeira fase temos cinco instanciações: coidado 'cuidado, zelo', costumado 'costume', mandado 'ordem', pecado 'violação de preceito religioso', reinado 'reino'. Na segunda, sete 
instanciações: criado 'serviçal', cuydado 'encargo, responsabilidade', gemidos 'lamentações', mandado 'ordem', prellados 'título honorífico de entidades clericais', rreinado 'período de governo de um rei', ruydo 'barulho'.

Do total dos substantivos derivados de formas participiais, quatro foram gerados no próprio latim: coidado (do lat. cogitatus, i), mandado (mandatum, i), pecado (do lat. peccatum, i), ruído (do lat. rugitus, us). Esses exemplos demonstram que a focalização é um processo cognitivo básico, já atuando em formas latinas.

\section{Considerações finais}

A descrição das instanciações de esquemas sufixais no português arcaico demonstra que a instauração da convencionalidade faz-se pela interação dos diversos domínios sociais, relacionada ao uso e à organização hierárquica dos mapas lexicais, ou seja, a organização dos operadores morfolexicais em redes esquemáticas que se associam por relações de projeção metafórica e metonímica.

Em todo o caso, o papel do uso é fundamental para a modelagem final dos produtos lexicais, que assim adquirem uma configuração muito mais rica do que aquela que apresentaria se ficassem limitados a regras de formação de palavras impostas pelos componentes funcionais de bases e afixos como se propunha em outro paradigma teórico.

O uso assegura, pois, a diversidade necessária a toda organização e funcionamento das línguas que, por inerência, dão lugar de relações hierárquicas em constante estruturação, potencializando um sistema linguístico heterogêneo. Essa mobilidade e maleabilidade do sistema derivacional sufixal do português arcaico foi aqui atestada pela análise de dados coletados sobre um corpus diversificado, representativo da primeira e segunda fases do português arcaico.

Enfim, é sobre dados empíricos, aplicados a uma metodologia ainda em construção, que pretendemos investigar todo o mapa de esquemas derivacionais sufixais e das relações semânticas que os engendram, no período arcaico. Este estudo, portanto, é apenas o começo de um trabalho ainda mais amplo a ser concluído. 


\section{Referências bibliográficas}

BOOIJ, Geert. Morphological analysis [to appear In: HEINE, Bernd; NARROG, Heiko (eds.). The Oxford Handbook of Grammatical Analysis. Oxford: Oxford University Press, 2009. p. 563-589.

BOOIJ, Geert. Construction Morphology. Language and Linguistics Compass, 3/1, p. 1-13, 2010. DOI: $10.1111 /$ j.1749-818x.2010.00213.x

BOOIJ, Geert. Morphology in Construction Grammar [to appear In: HOFFMANN, Thomas; TROUSDALE, Graeme (eds.) The Oxford Handbook of Construction Grammar. Oxford: Oxford University Press], 2012.

BOOIJ, Geert. Inheritance and motivation in Construction Morphology. In: GISBORNE, Nikolas; HIPPISLEY, Andrew (eds.). Defaults in morphological theory. Oxford: Oxford University Press, 2014.

BROWN, Roger. Social psychology. New York: Free Press, 1965.

BYBEE, Joan L. Regular morphology and the lexicon. Language and Cognitive Processes, v. 10, p. 425-55, 1995.

BYBEE, Joan. Lexicalization of sound change and alternating environments. In: Papers in Laboratory Phonology V: Acquisition and the Lexicon. BROE, Michael B.; PIERREHUMBERT, Janet B. (ed). Cambridge University Press. 2000. p. 250-268.

CROFT, William. Construction grammar. In: GEERAERTS, Dirk; CUYKENS, Hubert. The Oxford handbook of cognitive linguistics. New York: Oxford University Press, 2007. p. 463-508.

DOWNING, Pamela. On 'basic levels' and the categorization of objects in English discourse.

Berkeley Linguistics Society, v. 3, p. 475-87, 1977.

GONÇALVES, C. A. V.; ALMEIDA, M. L. L. Morfologia construcional: principais ideias, aplicação ao português e extensões necessárias. Alfa (ILCSE/UNESP), v. 56, n. 3, 2013.

GOLDBERG, Adele E. Constructions: a construction grammar approach to argument structure. Chicago: University of Chicago Press, 1995.

LANGACKER, Ronald W. Foundations of Cognitive Grammar. vol 1. Theoretical prerequisites. Stanford: Stanford University Press, 1987.

LANGACKER, Ronald W. Foundations of Cognitive Grammar. vol 2. Descriptive application. Stanford: Stanford University Press, 1991.

MATTOS E SILVA, Rosa Virgínia. Estruturas trecentistas: elementos para uma gramática do português arcaico. Lisboa: IN-CM, 1989. 
RIO-TORTO, Graça Maria. Morfologia derivacional: teoria e aplicação ao português. Porto, Porto Editora, 1999.

RIO-TORTO, G. M. et al. Gramática derivacional do português. Coimbra: Imprensa da Universidade de Coimbra, 2013.

ROSCH, Eleanor et. al. Basic objects in natural categories. Cognitive Psychology, v. 8, p. 382439, 1976.

SAID ALI, Manoel. Gramática histórica da língua portuguesa. São Paulo: Melhoramentos, 1966.

SOLEDADE, Juliana. Aspectos morfolexicais do Português arcaico - Sufixação nos sécs. XIII e XIV. Dissertação (Mestrado em Letras, área de Linguística Histórica). Universidade Federal da Bahia. 2 tomos, 2001.

SOLEDADE, Juliana. Semântica morfolexical. Contribuições para a descrição do paradigma sufixal do português arcaico. Tese (Doutoramento em Letras, área de Linguística Histórica). Universidade Federal da Bahia. 2 tomos, 2004.

SOLEDADE, Juliana. Experimentando esquemas: um olhar sobre a polissemia das formações [Xi EIR-]Nj no português arcaico. Revista Diadorim / Revista de Estudos Linguísticos e Literários do Programa de Pós-Graduação em Letras Vernáculas da Universidade Federal do Rio de Janeiro. Número especial, 2013.

TUGGY, David. Schematicity. In: GEERAERTS, Dirk; CUYKENS, Hubert. The Oxford handbook of cognitive linguistics. New York: Oxford University Press, 2007. p. 82-116. 